\title{
Treasury Inflation-Indexed Debt: A Review of the U.S. Experience ${ }^{1}$
}

\author{
Brian Sack \\ Division of Monetary Affairs \\ Board of Governors of the Federal Reserve System
}

and

Robert Elsasser

Markets Group

Federal Reserve Bank of New York

June 4, 2002

\footnotetext{
${ }^{1}$ This paper benefited from numerous conversations with Jim Clouse and Doug Elmendorf, as well as other members of the staff of the Board of Governors, the Federal Reserve Bank of New York, and the Treasury. We thank Patrick Dwyer, Bill English, Michael Fleming, Kenneth Garbade, Jeff Huther, Dino Kos, Deborah Perelmuter, Vincent Reinhart, and David Wilcox for valuable suggestions and comments. The opinions expressed are those of the authors and do not necessarily reflect the views of any other members of the Federal Reserve System.
} 


\title{
Treasury Inflation-Indexed Debt: A Review of the U.S. Experience
}

\begin{abstract}
This paper reviews the U.S. experience with inflation-indexed debt. To date, Treasury inflation-indexed securities have not been highly valued by investors, with the spread between the yields on nominal and inflation-indexed securities falling consistently below most measures of long-run inflation expectations. A number of factors might have contributed to the low relative valuation of TIIS, including the difficulty for investors of adjusting to a new asset class, the concentration of participation in the market, the lower liquidity of TIIS relative to nominal Treasury securities, and the divergent trends in the supply of nominal and inflation-indexed Treasury debt. As a result, inflation-indexed debt has not yet lived up to one of its main purposes - to reduce financing costs to the Treasury. However, there are signs that the TIIS market is still evolving, which could affect the valuation of TIIS going forward.
\end{abstract}

Robert Elsasser

Markets Group

Federal Reserve Bank of New York

New York, NY 10045

robert.elsasser@ny.frb.org
Brian Sack

Division of Monetary Affairs

Federal Reserve Board of Governors

Washington, D.C. 20551

bsack@frb.gov 


\section{Introduction}

In January 1997, the U.S. Treasury began issuing inflation-indexed debt securities (TIIS), which are debt securities with coupon and principal payments that adjust in line with a measure of consumer prices. Since that time, the Treasury has issued $\$ 130$ billion of inflation-indexed securities with maturity dates ranging from 2002 to 2032 . Some market participants have questioned the benefits of the TIIS program. In May 2001, just over four years after that program was initiated, the Treasury Advisory Committee of the Bond Market Association recommended that the Treasury discontinue issuance of inflation-indexed securities. ${ }^{2}$ Despite this advice, the Treasury reaffirmed its commitment to the TIIS program in February 2002 and indicated that it would seek ways to further develop that market. ${ }^{3}$ This paper discusses the U.S. experience with inflation-indexed debt to date and provides some insight into the hurdles that the program faces going forward.

Inflation-indexed debt held the promise of providing benefits to both investors and

the Treasury. Investors would benefit from having access to a new type of asset that reduces the risks associated with inflation. By purchasing inflation-indexed securities, investors could lock in a real rate of return-measured in terms of the amounts of goods and services that can be purchased-over the maturity of the security, thereby protecting themselves against the possibility that an unexpected rise in inflation would erode the real return realized on a nominal debt security. ${ }^{4}$ Moreover, the Treasury's willingness to issue such securities, it was argued, might provide a benchmark that would spur private issuance of inflation-indexed securities.

\footnotetext{
${ }^{2}$ See the May 1, 2001 Report to the Secretary of the Treasury from the Treasury Advisory Committee of the Bond Market Association. The Treasury Advisory Committee submits these reports to the Secretary of the Treasury before each mid-quarter refunding announcement. The Treasury is not required to follow the recommendations of the committee, but it frequently does so.

${ }^{3}$ See the February 2002 Quarterly Refunding Statement by the Treasury and the comments that day by Brian Roseboro, Assistant Secretary for Financial Markets at the Treasury.

${ }^{4}$ Investors cannot precisely lock in a real return because of taxes and the indexation lag on TIIS.
} 
The Treasury would also benefit, it was argued, because issuing inflation-indexed debt would likely reduce its financing costs. The argument was that investors typically demand a higher return on nominal debt securities to compensate them for the risks associated with future inflation. By issuing inflation-indexed debt, the Treasury would eliminate that risk for investors and would therefore avoid having to pay this "inflation risk premium," which should lower its financing costs. ${ }^{5}$

In addition, some argued that issuing indexed debt would have some ancillary benefits by providing policymakers and market participants with a useful reading of real interest rates. In that case, comparing the yields on TIIS to those on nominal securities would provide a measure of the amount of compensation that investors demand to offset future inflation and the associated risks, which might prove useful to monetary policymakers.

Despite their potential appeal, TIIS have not been highly valued by investors to date. Indeed, TIIS yields have been chronically high relative to those on comparable nominal Treasury securities, with the spread between nominal and TIIS yields falling well below many measures of long-run inflation expectations. This finding suggests that there is not a large positive inflation risk premium on nominal securities. In addition, the low relative valuation of TIIS to date may be partly attributable to the difficulty for investors of adjusting to a new asset class, the concentration of participation in the market, the low liquidity of TIIS relative to nominal Treasury securities, and the divergent trends in the supply of nominal and inflation-indexed Treasury debt. Below we describe the evolution of activity in the TIIS market since its inception and present some evidence on these factors.

Some of the factors that have weighed on TIIS prices appear to be changing over time. For example, there is evidence that the investor base for TIIS has broadened and that

\footnotetext{
${ }^{5}$ Another argument for issuing inflation-indexed debt is that it might help commit the government to maintaining low inflation. However, this incentive mechanism is generally seen as less important at this time for the United States.
} 
liquidity has improved in recent years. Nevertheless, TIIS will likely never achieve the same liquidity as nominal Treasury debt, largely because of the different roles that the two types of securities play in financial markets. As we discuss below, TIIS are primarily held by "end users," or investors who tend to buy and hold the instruments. By contrast, nominal Treasury securities (especially recently issued ones) are to a large extent used as hedging and trading instruments, with primary dealers playing a very active role in the market. ${ }^{6}$

Because of the low valuations of TIIS relative to nominal securities, inflationindexed debt has not yet lived up to its purpose of reducing financing costs for the Treasury. The results presented below suggest that based on inflation through mid-May 2002, the TIIS program cost the Treasury about $\$ 1$ billion more than if the Treasury had issued comparable nominal securities. Moreover, we find that future CPI inflation would have to come in at 1.8 percent for the Treasury to break even on the TIIS securities that are currently outstanding. Several private forecasts have expected long-run inflation in the vicinity of 2.5 percent, in which case it appears that the Treasury has paid about 70 basis points of additional financing cost on the outstanding TIIS relative to comparable nominal securities. Of course, debt managers should be more concerned about the relative cost of future TIIS issuance, which is difficult to predict.

\section{The Mechanics of TIIS}

The characteristic that distinguishes Treasury inflation-indexed securities from nominal debt securities is that the principal amount on the TIIS is adjusted over time based on the rate of consumer price inflation. Specifically, the value of the principal on a given day is scaled up by an index ratio that is determined by dividing the reference CPI for that day by the reference CPI at the time of issuance. The reference CPI on the first of the month is the non-seasonally adjusted CPI index published by the Bureau of Labor Statistics for the

\footnotetext{
${ }^{6}$ For a broader overview of the Treasury securities market, see Dupont and Sack (1999).
} 
third preceding calendar month, and its value within the month is determined by linear interpolation. Thus, the principal value of the TIIS on any given day increases by an amount determined by the increase in the CPI measure between the third and second preceding months - the minimum indexation lag possible given the timing of the CPI data release. Coupon payments on TIIS are determined as a fixed percentage of the indexed principal amount and therefore also increase in line with the index ratio.

Because of this indexation, the nominal payments on the indexed security are backloaded relative to those on a nominal security (assuming that the rate of inflation is positive). An indexed security issued at time $t$ with a coupon rate of $c$, a maturity of $N$ years, and a par value of $\$ 100$ has coupon payments after $n$ years of $c \cdot 100 \cdot P_{t+n} / P_{t}$, where $P_{t+n}$ is the reference CPI at time $t+n$, and a principal payment after $N$ years of $100 \cdot P_{t+N} / P_{t}$. (For notational simplicity, we assume that coupons are paid annually and ignore semi-annual compounding.) This back-loaded pattern allows the real coupon payments, $c \cdot 100$, to be constant.

The Pricing of TIIS. If future inflation were known, the price of the inflationindexed security at time $t, B_{t}$, would be determined by the sum of future nominal payments multiplied by the value of those payments, as follows:

$$
B_{t}=\sum_{n=1}^{N} c \cdot 100 \cdot\left(P_{t+n} / P_{t}\right) \cdot \delta_{t}(n)+100 \cdot\left(P_{t+N} / P_{t}\right) \cdot \delta_{t}(N),
$$

where $\delta_{t}(n)$ is the discount function, which equals the value at time $t$ that investors place on a nominal payment $n$ periods into the future. ${ }^{7}$ The discount function is determined by the term structure of nominal interest rates $\delta_{t}(n)=1 /\left(1+i_{t}^{n}\right)^{n}$, where $i_{t}^{n}$ is the $n$-period zero-

\footnotetext{
${ }^{7}$ We have scaled the security to have an index ratio of 1 at time $t$. Otherwise, all payments would be scaled up by $\mathrm{P}_{t} / \mathrm{P}_{\mathrm{i}}$, where $\mathrm{P}_{\mathrm{i}}$ is the reference CPI at the time of issuance. We also assumed that the first coupon payment is exactly one period away. Otherwise, (1) represents the dirty price of the security, which would have to be adjusted for accrued interest and inflation compensation to arrive at the quoted (clean) price.
} 
coupon nominal interest rate at time $t$. Rewriting the index ratio $P_{t+n} / P_{t}$ as $\left(1+\pi_{t}^{n}\right)^{n}$, where $\pi_{t}^{n}$ as the average annualized rate of inflation over the next $n$ periods, and writing out the discount function, equation (1) becomes

$$
B_{t}=\sum_{n=1}^{N} \frac{c \cdot 100 \cdot\left(1+\pi_{t}^{n}\right)^{n}}{\left(1+i_{t}^{n}\right)^{n}}+\frac{100 \cdot\left(1+\pi_{t}^{N}\right)}{\left(1+i_{t}^{N}\right)^{N}}
$$

To derive a simpler equation for TIIS, define the $n$-period zero-coupon real interest rate $r_{t}^{n}$ by the following: ${ }^{8}$

$$
\left(1+r_{t}^{n}\right)=\frac{\left(1+i_{t}^{n}\right)}{\left(1+\pi_{t}^{n}\right)}
$$

Using this definition, equation (2) becomes

$$
B_{t}=\sum_{n=1}^{N} \frac{c \cdot 100}{\left(1+r_{t}^{n}\right)^{i}}+\frac{100}{\left(1+r_{t}^{N}\right)^{N}},
$$

which states that the TIIS is valued like a regular bond with a fixed coupon of $c$, only discounted using real interest rates rather than nominal rates. Note that the real payments on the TIIS security are independent of inflation, so that equation (3) holds regardless of whether future inflation is known. In practice, the quoted yield on a TIIS is the real yield-tomaturity on the security, which is the constant real interest rate $r^{y t m}\left(r^{n}=r^{y t m}\right.$ for all $\left.n\right)$ for which equation (4) holds.

The spread between the yield on a TIIS and that of a comparable nominal security will reflect investors' views about future inflation. If future inflation is known, the $N$-period returns on two investments—one making a real payment in $N$ periods and one making a nominal payment—must be equal, which implies that

$$
(1+r)^{N}=\left[\frac{(1+i)}{(1+\pi)}\right]^{N}
$$

\footnotetext{
${ }^{8}$ Note that this equation implicitly defines a real discount function $\delta^{r}(n)=\delta(n) \cdot\left(1+\pi^{n}\right)$.
} 
(We have dropped the subscripts and superscripts for notational simplicity.) This equation will be approximately satisfied if $i-r=\pi$. Thus, in this case the yield spread between comparable nominal and indexed zero-coupon securities should (approximately) equal the future rate of inflation.

Equation (5) would hold for zero-coupon yields, and hence for the valuation of all of the individual payments on the TIIS security. The relationship is more complicated for the yields-to-maturity on coupon-bearing bonds. However, under the additional assumption that inflation is expected to be relatively stable around some level $\pi$, the following relationship still holds:

$$
\left(1+r^{y t m}\right)=\frac{\left(1+i^{y t m}\right)}{(1+\pi)},
$$

where $i^{y t m}$ is the nominal yield that investors would demand on a security with the same back-loaded payment stream as the TIIS.

In the case of coupon-bearing securities, the choice of the appropriate nominal security to compare to the TIIS is not obvious. The most common practice is to use a nominal coupon security with the same maturity as the TIIS. However, those two securities have different payment flows: The nominal payments on the TIIS are much more backloaded than those of a standard nominal coupon security; in real terms, the coupon payments on the nominal security decline over time, unlike the constant real coupon payments on a TIIS. Sack (2000) instead derives a measure of inflation compensation based on a portfolio of nominal zero-coupon securities (read off an estimated yield curve) constructed to match the back-loaded payments of the TIIS. Nevertheless, as demonstrated in that paper, the resulting measure differs only modestly from a simple yield spread based on a nominal coupon security. ${ }^{9}$

\footnotetext{
${ }^{9}$ That paper argues that a more important factor is choosing a nominal security with a level of liquidity that is comparable to the TIIS.
} 
Uncertainty about Inflation. One complication with interpreting inflation

compensation measures involves uncertainty about future inflation. If investors are risk neutral, then they will demand the same expected real return on nominal and inflationindexed zero-coupon securities. In that case, equation (5) becomes:

$$
(1+r)^{N}=E_{t}\left[\frac{(1+i)^{N}}{(1+\pi)^{N}}\right],
$$

which can be rewritten approximately as follows:

$$
i-r=\frac{1}{E_{t}\left[\frac{1}{(1+\pi)^{N}}\right]^{1 / N}}-1 .
$$

According to equation (8), inflation uncertainty tends to pull inflation compensation down relative to the expected rate of inflation. To see that, note that Jensen's inequality implies that

$$
E_{t}\left[\frac{1}{(1+\pi)^{N}}\right]>\left[\frac{1}{\left(1+E_{t} \pi\right)^{N}}\right] .
$$

As a result, the yield spread will be less than the expected rate of inflation,

$$
i-r<E_{t} \pi
$$

by an amount that increases with the uncertainty surrounding future inflation. ${ }^{10}$

For a coupon-bearing security, the total effect is a bit more complicated-equation (8) shows the impact of uncertainty on the value of any single payment, and those effects have to be aggregated across all of the payments on the security. For a reasonable range of uncertainty about future inflation (see section 5), this effect decreases the ten-year inflation compensation measure by 2 to 11 basis points. ${ }^{11}$

\footnotetext{
${ }^{10}$ This point was originally made by Fischer (1976). A more detailed description of the relationship between inflation compensation and future inflation can be found in McCulloch and Kochin (1998).

${ }^{11}$ These estimates are based on simulations assuming a range for the standard deviation of annualized ten-year inflation of 0.57 to 1.49 percentage points, as described in section 5 .
} 
While convexity tends to pull down inflation compensation relative to expected inflation, there may be an inflation risk premium that works in the opposite direction. If investors are not risk neutral, they will generally not demand the same expected return on the two securities. Because future inflation erodes the real payments on a nominal security but not on the TIIS, one might expect investors to demand a higher expected return on nominal securities when future inflation is uncertain. Such a risk premium would push the yield spread $i-r$ up relative to expected inflation, thereby increasing the financing cost to the Treasury on nominal debt securities. Indeed, this was one of the primary arguments for issuing TIIS, as discussed in the introduction.

Deflation Protection and the Option Value of TIIS. A final complication in interpreting the nominal-indexed yield spread arises from a condition that protects TIIS investors against deflation. The TIIS program assures that the cumulative adjustment to the principal amount of the inflation-indexed security at maturity will not be negative. Thus, in nominal terms, the holder of a TIIS earns the return $r$ (the real yield) plus a payment equal to the cumulative amount of inflation over the period. However, the payment based on cumulative inflation has a floor at zero-a structure that is equivalent to the payout on a call option. ${ }^{12}$ Thus, the investor essentially has a long position in a call option on cumulative inflation with a strike of zero. As positive inflation accrues over the life of the TIIS, this call option moves increasingly "in the money." Given that inflation is typically positive, the call option may be perceived to be far enough in the money that owning the call is essentially equivalent to owning the underlying asset. In that case, one can ignore the option value in assessing the spread between nominal and inflation-indexed debt. Note that the option value only applies to the principal payment, as the coupon payments can decline with deflation.

\footnotetext{
12 TIIS contain a call option on inflation in terms of nominal returns. In terms of real returns, TIIS contain a put option on inflation. The reason for this relationship is put-call parity, which roughly states that owning a call and having a short position in the underlying asset is equivalent to owning a put. Moving from nominal returns to real returns is equivalent to taking a short position in inflation, which, combined with the call, yields a long position in a put option.
} 


\section{Activity in the TIIS Market}

The TIIS program got off to an impressive start. The program's inaugural auction of a ten-year note in January 1997 was very well received by investors, creating a brief period of enthusiasm for the new asset class. The bid-to-cover ratio at the first auction registered an impressive 5.3, compared to only 2.4 and 1.9 for the preceding and subsequent nominal tenyear note auctions, respectively. Moreover, the stop-out rate on the inaugural auction was 3.449 percent, which was more than 3 percentage points below the yields on comparable nominal Treasury securities. ${ }^{13}$

The spread between nominal and TIIS yields that prevailed over the first several months would in fact be the widest level observed during the TIIS program to date. Figure 1 shows the history of the yields on nominal and inflation-indexed ten-year Treasury securities, where an off-the-run nominal yield is used to limit the difference in the liquidity of the nominal and indexed securities. ${ }^{14}$ The bottom panel shows a measure of ten-year inflation compensation based on the difference between the nominal and indexed yields. ${ }^{15}$ As is evident from the figure, the inflation compensation measure averaged about $3 \frac{1}{4}$ percent over the first several months of 1997, which was greater than the prevailing level of inflation expectations from various surveys. In response to the favorable valuation of indexed debt, the initial Treasury offering was followed by a flurry of other borrowers issuing inflationindexed securities of their own. Between February and July 1997, 15 different U.S. nonTreasury issuers offered a total of $\$ 2.3$ billion of inflation-indexed securities.

The enthusiasm for inflation-indexed debt was not long-lived, though. Inflation compensation fell steadily over 1997 (figure 1), reaching a level of about 2 percent during

\footnotetext{
${ }^{13}$ As another indication of the unexpectedly strong demand, the stop-out rate was almost 4 basis points less than the prevailing when-issued quote at the auction close time. The behavior of TIIS over the first several months following the first auction is described in more detail in Wilcox (1998).

${ }^{14}$ The nominal yield is a par yield read from an estimated yield curve.

${ }^{15}$ This measure is computed using the payment-matching method described in Sack (2000), although we use a zero-coupon yield curve estimated from off-the-run notes and bonds and coupon STRIPS, rather than the pure STRIPS curve used in that paper.
} 
the first half of 1998. This decline may partly reflect that the strongest demand for TIIS-by those investors willing to give up the largest amount of yield to hold inflation-indexed rather than nominal securities—was quickly saturated. In addition, the fall in inflation compensation may be partly attributed to a broad decline in inflation expectations. In 1997, various currency crises abroad and concerns about a global economic slowdown, particularly in Asia, dominated market attention. As commodity prices plummeted and the dollar surged, inflation indicators consistently fell below expectations. Figure 2 shows the actual headline CPI figure and the unexpected component of the monthly CPI release calculated from a Bloomberg survey of market participants. Throughout this period, inflation declined to very low levels and consistently surprised market participants to the downside. In this environment investors apparently had little interest in purchasing the inflation protection offered by TIIS. Moreover, private issuance of inflation-indexed securities dried up and has remained minimal ever since.

In the fall of 1998 , financial market volatility abroad spread to U.S. financial markets, causing investors to place great value on the liquidity of their portfolios. The increased preference for liquidity at that time pushed down nominal yields relative to TIIS yields, given that nominal securities are more liquid (as discussed below). On-the-run nominal Treasury securities (that is, the most recently issued securities) were viewed as the ultimate liquid instruments, but even off-the-run Treasuries benefited, which contributed to the sharp decline in their yields (figure 1). In contrast, yields on TIIS dipped only modestly, as trading activity in TIIS was reportedly viewed as too limited to provide the flexibility needed in such unpredictable market conditions. As a result, inflation compensation fell to a remarkably low level, reaching a trough of 88 basis points in October 1998.

Over the first half of 1999 , some of the factors that may have been limiting the appeal of TIIS began to unwind. CPI inflation turned higher and began to show some upward momentum (figure 2), in part due to considerable increases in energy prices. In 
addition, investors' preference for liquidity, while still elevated, fell back from its extreme levels. In response, inflation compensation rose sharply over the first half of 1999.

Since the second quarter of 1999 , movements in nominal and TIIS yields appear to have become more correlated, and inflation compensation has remained in a narrower range — typically between $1 \frac{1}{2}$ and $2 \frac{1}{2}$ percent — in contrast to the wide swings seen during the first two years of the TIIS program. ${ }^{16}$ Inflation compensation edged higher over most of 1999 , as the economy grew at a rapid pace, and reached a new peak of over $2 \frac{1}{2}$ percent in May 2000, when concerns about inflation seemed to crest. As the growth of the economy moderated over the latter part of 2000, real interest rates and inflation compensation drifted lower. Once it became apparent late in 2000 that the economy was slowing more rapidly, both real interest rates and inflation compensation fell considerably, although inflation compensation retraced part of that decline after the Federal Reserve began to ease monetary policy in early 2001. Except for a sharp run-up in the spring of 2001, inflation compensation remained at fairly low levels over 2001, consistent with the decrease in inflation pressures arising from the economic slowdown.

Additional information about real interest rates can be obtained by looking at the term structure of TIIS yields. Three snapshots of the TIIS yield curve are shown in figure 3: one from mid-2000, one from the day before the easing cycle began in January 2001, and one from a more recent date in February 2002. As might have been expected, expectations of the easing of monetary policy pulled down the TIIS yield curve from mid-2000 to early 2001. In the event, the actual policy easings pushed down shorter-term TIIS yields even further, causing the TIIS yield curve to steepen appreciably through early 2002. The policy

\footnotetext{
${ }^{16}$ Indeed, since the second quarter of 1999, TIIS yields appear to have provided a more reasonable measure of real interest rates, and inflation compensation a more useful indicator of inflation expectations (subject to the limitations of interpreting inflation compensation in this manner).
} 
easing was aggressive enough to push the yield on the TIIS maturing in 2002 all the way to zero, and even below zero. ${ }^{17}$

Activity in the TIIS market has also evolved in the past couple of years. Anecdotal reports suggest that interest in TIIS among investors has increased, particularly in 2000 and 2001. The investor base for TIIS has broadened, and secondary market liquidity has reportedly improved. These anecdotal reports are corroborated by data on trading volume collected by the Federal Reserve Bank of New York. Figure 4 shows weekly trading volume in TIIS reported by primary dealers as a percentage of total outstanding TIIS. As is evident, dealer-to-customer trading activity increased noticeably over this period, with the weekly turnover ratio reaching 6 percent on average in 2001, compared to an average of less than $3 \frac{1}{2}$ percent over 1999 . In dollar terms, trading volume increased even faster, given that the supply of TIIS was increasing considerably over this period.

But despite the reported increase in investor interest in TIIS, the average level of TIIS yields has been puzzlingly high relative to nominal Treasury yields. Indeed, the level of inflation compensation has consistently been below many survey measures of expected inflation. ${ }^{18}$ Table 1 shows the average quarterly level of the ten-year inflation compensation measure and a survey measure of ten-year inflation expectations from professional forecasters conducted by the Federal Reserve Bank of Philadelphia. On average, the marketbased inflation compensation has been about $1 \frac{1}{2}$ percentage point below the survey measure. This is the case even if we start the sample in the second quarter of 1999, when inflation compensation seemed to stabilize some.

\footnotetext{
${ }^{17}$ Note that there is no zero bound on the yield on TIIS, as there is on the yields of nominal securities, because the inflation compensation can result in a positive nominal return even when the real yield is negative. The yield on the 2002 TIIS fell well below zero after the date shown, in part because of the influence of energy prices on the index ratio.

${ }^{18}$ Some of the difference would be expected given the effects of uncertainty about future inflation, as explained in section 2. However, the realized differences appear too large to be explained entirely by this effect.
} 
The low level of inflation compensation is especially surprising if one believes that yields on nominal Treasury securities contain an inflation risk premium that would push their yields higher. Campbell and Shiller (1996) use the historical behavior of inflation and real interest rates in a CAPM model to estimate the inflation risk premium for the five-year nominal bond. ${ }^{19}$ Their results found that the inflation risk premium was estimated to be between $1 / 2$ and 1 percentage point. The actual behavior of TIIS instead suggests either that the inflation risk premium is negative, or that other factors (not captured by CAPM) have weighed on TIIS prices, as explored next.

\section{Factors Potentially Weighing on TIIS Prices}

The previous section noted that the value that investors have placed on TIIS relative to nominal Treasuries appears to be surprisingly low. This section takes a closer look at some of the (overlapping) factors that have likely weighed on TIIS prices.

Newness. The low valuations of TIIS may, in part, reflect the difficulties associated with launching a new type of asset. For example, the securities are somewhat complex and likely require a non-trivial investment in a potential buyer's infrastructure (such as accounting and trading systems), thereby hindering the expansion of the investor base. Evidence of this assertion may be found in the general collateral (GC) repo market, in which TIIS GC repo typically trades a few basis points above similarly dated nominal Treasury GC repo, despite TIIS being a theoretically preferred type of collateral due to its lower price volatility. Furthermore, as a relatively new security type, the absence of a historical track record makes it difficult for potential investors to evaluate the behavior of TIIS, including the likely volatility of TIIS prices and their correlation with other asset prices.

If this were the only factor present, one might expect to see the investor base broaden and the relative value of TIIS to improve over time. Indeed, TIIS have now traded

${ }^{19}$ Similarly, Kopcke and Kimball (1999) evaluate the role of TIIS in efficient investor portfolios. 
in the market for over five years, giving academics and investment advisors more experience to understand and adjust to the asset class. While there is some evidence of a widening investor base, there is no evident improvement in the relative value of TIIS over time.

Concentration of Participation. Data on the distribution of end-users of TIIS are not available, but anecdotal reports suggest that the investor base for TIIS is much more concentrated than that for nominal Treasuries. Indeed, a relatively small set of investors reportedly holds the majority of outstanding securities and accounts for a sizable portion of market activity. As expected, the primary participants in the market are large institutional investors such as pension funds and insurance companies-investors with significant amounts of long-term real liabilities that can be counterbalanced by holding long-term real assets. Nevertheless, participation in the market is reportedly expanding, with some dealers reporting that the number of medium- to large-sized customers in the TIIS market has more than doubled over the past two years.

Small investors have had fairly limited participation in the TIIS market, although that participation may be increasing of late as well. There are at least six different mutual funds holding inflation-indexed securities that are available to small investors. The most recent data available from these funds indicate that they have a total of about $\$ 6$ billion in assets. These holdings represent a modest amount of the outstanding TIIS, although some of the funds are growing rapidly, and new ones are currently forming.

Notably, the primary dealers, which are the major participants in the market for nominal Treasury securities, are (with a few exceptions) relatively inactive in the market. The absence of the primary dealers largely reflects the fact that TIIS do not play the same role as hedging and trading vehicles that nominal Treasuries do, in part because of the absence of private inflation-indexed debt that needs to be hedged. As a result, dealer positions in TIIS pale in comparison to those in nominal securities. Over 2001, for example, the primary dealers in total had a daily average of $\$ 104$ billion in long positions in nominal 
Treasury coupon securities and $\$ 137$ billion in short positions. By comparison, those same dealers had only $\$ 5.8$ billion in long positions in TIIS and $\$ 2.4$ billion in short positions, on average.

In addition to the lower level of overall dealer activity for TIIS, trading volumes in TIIS is concentrated among a small number of dealers. The share of total TIIS transaction volume among the top quintile of primary dealers averaged 80.0 percent in 2001, compared to 53.9 percent for nominal Treasury securities. Moreover, the concentration has increased slightly as the market has matured.

Further evidence of the greater appeal of TIIS to institutional investors than to primary dealers is available from the awards at Treasury auctions. Over 2000 and 2001, an average of 77.5 percent of the awards at auctions of nominal ten-year Treasury notes has gone to primary dealers, and only 8.2 percent has gone directly to institutional investors such as mutual funds, pension funds, and insurance companies. By contrast, at ten-year TIIS auctions over that period, 54.7 percent of the awards went to primary dealers, with 30.5 percent instead going to those types of institutional investors. ${ }^{20}$

Liquidity. Liquidity in the TIIS market has been somewhat limited, which is another factor that has likely weighed on the value of TIIS. ${ }^{21}$ As is evident from figure 4 (shown earlier), most of the trading in the TIIS market takes place between dealers and customers, reflecting that activity in the market is dominated by end-users who might find the securities appealing as an investment vehicle (a buy-and-hold asset). The volume of trading between dealers is instead relatively low, in part because dealers do not use these securities for trading and hedging purposes, as mentioned above.

\footnotetext{
${ }^{20}$ Of course, primary dealers also bid to cover short positions that they have established by selling the security in the when-issued market, so many of their awards will essentially be passed on to other investors.

${ }^{21}$ The effect of liquidity on the relative valuation of TIIS is discussed by Shen and Corning (2002).
} 
Liquidity in the TIIS market appears to be improving over time, as evidenced by the increase in trading volume in recent years. However, trading activity in TIIS remains below the levels observed for some other types of fixed income assets. The weekly turnover rate, which is defined as the total weekly volume (including dealer-dealer and dealer-customer transactions) as a percentage of outstanding debt, averaged 7.7 percent for TIIS over 2001. The TIIS turnover rate fell below the 11.7 percent average rate for agency coupon securities and the 20.3 percent rate for mortgage-backed securities over that period, and well below the 41.2 percent average turnover for nominal Treasury securities.

Of course, most of the trading activity in nominal Treasury securities takes place in the on-the-run issues, which turned over more than 16 times each week on averaged in 2001 and accounted for 81 percent of the total Treasury volume reported by dealers over that period. The TIIS turnover rate was only slightly below that of all off-the-run Treasury securities, which was 8.1 percent over that period. Nevertheless, TIIS appear to be somewhat less liquid than off-the-run nominal Treasury securities when liquidity is measured by transaction costs. Table 2 summarizes indicative bid-ask spreads observed for TIIS and for both on-the-run and off-the-run nominal Treasury securities. Bid-ask spreads on TIIS are much wider than those for on-the-run nominal Treasuries, as expected, and are typically somewhat wider than those for off-the-run nominal securities as well.

Relative Supply. The amount of outstanding marketable Treasury debt reached its peak in March 1997, after which surprisingly high tax receipts pushed the federal budget into surplus. On net from March 1997 through March 2002, the Treasury paid down $\$ 688$ billion of nominal Treasury coupon securities, or 26 percent of the outstanding stock. In contrast, the supply of TIIS increased from zero at the beginning of 1997 to more than $\$ 145$ billion (including inflation accrual) by March 2002.

The divergent trends for supply may have impacted the relative pricing of these securities. Indeed, the market at times appeared to struggle with the transition to a smaller 
nominal Treasury market, resulting in a heightened premium for nominal Treasuries relative to other fixed income securities. At the same time, the market had to absorb a relatively large amount of TIIS, despite the unfamiliarity of many investors with that asset class.

\section{The Cost of TIIS to the Treasury}

The seemingly low valuation of TIIS relative to nominal debt securities has important implications for the relative cost of those securities to the Treasury. This section provides some estimates of the cost to the Treasury of having issued the outstanding TIIS relative to the cost that it would have incurred if it had instead issued nominal securities.

While the above analysis compared TIIS yields to off-the-run nominal securities for information purposes, the relevant comparison from the perspective of financing costs is between TIIS and on-the-run nominal issues. The Treasury typically benefits from a liquidity premium that lowers the yields on its on-the-run nominal issues, and hence the cost of nominal debt relative to TIIS. The difficulty in obtaining cost estimates is in specifying the counterfactual, or the issuance strategy that the Treasury would have followed in the absence of TIIS. We take two separate approaches.

Approach 1: Static Issuance Strategy. Because the payment flows on nominal and inflation-indexed securities differ considerably, there is no obvious choice of a nominal security for comparison to the TIIS. One might be tempted to compare TIIS to nominal debt securities with the same maturity, but (as discussed above) the nominal coupon security has declining real coupon payments that will give it a shorter duration than the TIIS. To minimize the impact of differences in payments, we instead compare the cost of each outstanding TIIS to the cost of a portfolio of hypothetical on-the-run zero-coupon nominal securities that replicates the back-loaded payments on the TIIS. ${ }^{22}$ Of course, the Treasury

\footnotetext{
${ }^{22}$ This approach is the same method as that used above to construct the inflation compensation measure, only here using on-the-run zero-coupon securities rather than off-the-run ones. We do not
} 
would not follow such a strategy in the absence of TIIS, but would instead likely increase its issuance of a variety of on-the-run securities. Nevertheless, this approach effectively captures the cost of replacing issuance of TIIS with issuance of nominal on-the-run securities, while minimizing any effects arising from differences in their payment streams. ${ }^{23}$ The first step in the analysis is to calculate break-even inflation rates for each TIIS auction. This is the constant rate of inflation at which the cost to the Treasury of issuing a TIIS will exactly equal the cost of raising the same amount of funds by issuing the comparable nominal security (the portfolio of zero coupon securities). ${ }^{24}$ If inflation exceeds the break-even rate, the TIIS will be more costly than the nominal security, and vice-versa. The break-even inflation rates for all auctions (including reopenings) of TIIS to date are shown in column (5) of table 3. The highest break-even inflation rates were for the first two auctions of inflation-indexed securities (both of which were the ten-year note maturing in 2007). As mentioned above, this could reflect that those investors with the strongest demand for inflation protection were among the first to purchase TIIS. The lowest break-even inflation rates were for those securities issued around the financial market turbulence of the fall of 1998, perhaps due to the heightened preference for liquidity at that time. For auctions since the second quarter of 1999 , break-even inflation rates have remained in a narrower range, between 1.58 and 2.36 percent.

The cost of each TIIS issue to date depends on the difference between actual inflation and the break-even inflation rate. Column (6) of the table shows the inflation rate realized over the period since each auction, adjusted for the indexation lag and expressed on

consider the fact that the yields on nominal securities might have been higher if the Treasury had issued them in place of TIIS.

${ }^{23}$ The values of the hypothetical zero-coupon securities are derived from the constant-maturity yield curve estimated by the Treasury, which is based primarily on the yields of on-the-run securities. We thank the Treasury for providing the zero-coupon yield curve for the relevant dates. One concern is that this yield curve may be poorly estimated because of the limited number of data points.

${ }^{24}$ This is strictly true only if inflation is constant over the maturity of the security. Allowing for a time-varying path of inflation would require additional assumptions. 
an annualized basis. Deviations of actual inflation from the break-even inflation rate generate a stream of differences in payments on the nominal and inflation-indexed securities over the maturity of those issues. In our computations, we express the relative cost of the TIIS as the present value of all past and future differences in the payments on the two securities. $^{25}$

Column (7) of the table shows this cost measure for each outstanding TIIS as of May 20, 2002 based on realized inflation through that date. As is evident, the largest cost savings to the Treasury occurred at the first two TIIS auctions (both of which are the note maturing in January 2007), which together have saved the Treasury just over $\$ 1$ billion. By contrast, the TIIS issued at all auctions from January 1998 to January 2000 have been more expensive than comparable nominal securities. The relative cost is especially high for those securities issued during the fall of 1998, when inflation compensation levels were remarkably low. Summing across all securities, the excess cost of all outstanding TIIS based on inflation to date is estimated to be just over $\$ 1$ billion. $^{26}$

While the calculations above only take account of realized inflation to date, it may also be useful to estimate the total cost of the program under different assumptions about inflation going forward. We find that future inflation would have to fall to 1.80 percent for the Treasury to break even on the TIIS program (in present value terms). ${ }^{27}$ Of course, most economic forecasts project that CPI inflation will come in well above this level. For example, CBO (2002) assumes a path of CPI inflation that settles at 2.5 percent after several years, which is consistent with the Federal Reserve Bank of Philadelphia survey discussed

\footnotetext{
${ }^{25}$ This method discounts future payment differences and compounds past payment differences using the Board estimated off-the-run yield curve. If the differences in payments were offset by altering the issuance of new securities, it would be more appropriate to use an on-the-run curve for discounting. However, if the differences are offset by buybacks, using the off-the-run curve is appropriate.

${ }^{26}$ One consideration that we ignore is that the Treasury recovers some of the additional interest it pays in the form of taxation on interest income.

${ }^{27}$ A similar result emerges if we focus on more recent auctions. The level of inflation needed to break even on just those TIIS issued since the second quarter of 1999 is 1.84 percent.
} 
earlier. If one believes that average CPI inflation going forward will be in the vicinity of 2.5 percent, then it appears that the Treasury has paid about 70 basis points of additional yield on TIIS than it would have on comparable nominal debt.

If we assume that future inflation will match the CBO's projection, we can compute the total cost of the TIIS program, or the present value of the differences in all past and futures payments on the securities. ${ }^{28}$ As shown in column (8), the results indicate that the Treasury will incur a higher relative cost on all but the first four TIIS auctions. The total cost of the inflation-indexed securities outstanding is estimated to be about $\$ 8$ billion under the $\mathrm{CBO}$ assumption for inflation.

Most of the excess cost of the TIIS program under these estimates results from future inflation, which is assumed to rise well above the range of break-even rates on outstanding TIIS. Of course, the appropriate assumption for the path of inflation could be debated, given the considerable uncertainty that surrounds such a long-term forecasting exercise. As mentioned above, if average future inflation instead came in at 1.80 percent, the outstanding TIIS would break even. Each 0.01 percentage point of additional inflation adds about $\$ 115$ million to the total estimated cost of the TIIS program.

Approach 2: Dynamic Issuance Strategy. One problem with the above approach is that it is a static exercise. Nominal debt issuance was assumed to take place at a single point in time, and differences in the payments of the indexed and nominal securities then accumulate based on realized inflation. This section instead evaluates the cost of an indexed security by considering a dynamic strategy for issuing standard (coupon-bearing) nominal securities that exactly replicates all of the payments of the indexed security up to its maturity date. The relative cost of nominal and indexed debt is then captured entirely by the single difference in the payments on the maturity date.

${ }^{28}$ We extrapolate a constant 2.5 percent rate of inflation beyond 2011. 
The basic insight to this approach is that the accrual of inflation compensation on indexed debt is similar to the issuance of additional debt, in that it increases the principal and all future coupon payments. We can formalize this idea by comparing the payments from issuing $\$ X_{t}$ of $N$-period inflation-indexed debt at time $t$ to a dynamic strategy of nominal debt issuance. The nominal debt strategy also begins by issuing $\$ X_{t}$ of an $N$-period nominal coupon-bearing security at time $t$, thereby raising the same amount of funds $\$ X_{t}$ at time $t$.

Denote the coupon rate at time $t$ on the nominal debt $C_{t}$, and the indexed debt coupon rate $c_{t}$. At time $t+1$, the nominal security will have a payment of $C_{t}^{*} X_{t}$, and the indexed debt will have a smaller coupon payment of $c_{t}^{*}\left(1+\pi_{t+1}\right)^{*} X_{t}$, where $\pi_{t+1}$ is the rate of inflation between $t$ and $t+1 .{ }^{29}$ To maintain the same payout under the two strategies at time $t+1$, the Treasury could issue the following amount of $(N-1)$-period nominal debt at time $t+1$ :

$$
X_{t+1}=X_{t} \cdot\left(C_{t}-c_{t}\left(1+\pi_{t+1}\right)\right)
$$

The net payout by the Treasury at time $t+1$ would then be $C_{t}^{*} X_{t}-X_{t+1}$, which, plugging in (11), is equal to $c_{t}^{*}\left(1+\pi_{t+1}\right) * X_{t}$, 一 the same payout as the indexed security.

Although the nominal strategy has matched the payment on the inflation-indexed debt at time $t+1$, the total liability of the Treasury due at maturity has likely increased by a different amount. Under the nominal strategy, the liability of the principal payment has gone up by $X_{t+1}$, compared to an increase of $\pi_{t+1} * X_{t}$ in the principal liability of the inflationindexed debt. The difference in the magnitudes of these liabilities reflects the difference in the costs of the two types of debt. The costs turn out to be the same if $X_{t+1}=\pi_{t+1} * X_{t}$. Using equation (13), this condition holds only if $\left(1+C_{t}\right) /\left(1+\pi_{t+1}\right)=1+c_{t}$, or if actual inflation equals the break-even inflation rate between the coupon rates on the nominal and indexed securities.

\footnotetext{
${ }^{29}$ We assume that $C_{t}>c_{t} \cdot\left(1+\pi_{t+1}\right)$ holds. Otherwise, the dynamic issuance strategy becomes a dynamic buyback strategy.
} 
This strategy can be repeated to replicate all the payments on an inflation-indexed security from time $t+1$ to time $t+N-1$ for any path of inflation. Thus, an advantage of this exercise is that it summarizes the difference in the costs of the nominal and indexed debt in a single payment at the maturity date. However, a disadvantage of the approach is that one must make assumptions not only about both the future path of inflation, but also about the future path of on-the-run nominal yields to arrive at a total cost estimate. In the results that follow, we again assume that inflation follows the path projected by the $\mathrm{CBO}$, and that nominal issuance takes place at a simple linear interpolation of the constant maturity yields at three- and six-month, two-, five-, ten-, and thirty-year maturities. For the future path of interest rates, we assume that the yield curve over the next two years reverts in a linear manner back to its average shape from 1995 to 2000 and then remains constant.

Table 4 summarizes the calculated cost of all outstanding TIIS relative to the dynamic nominal issuance strategy under those assumptions, which is given by the present discounted value of the difference in the payments at maturity. As in the static exercise, only the first four auctions of inflation-indexed securities are expected to result in a cost savings to the Treasury, while all other auctions are expected to cost the Treasury more than the dynamic issuance strategy for nominal debt. Summing across all outstanding securities, the total estimated cost of outstanding inflation-indexed debt is about $\$ 7.8$ billion-similar to the estimate from the static exercise.

Inflation Uncertainty. Although the above calculations suggest that TIIS appear to have been an expensive form of borrowing for the Treasury, the realized cost of TIIS will depend on the actual level of CPI inflation over the life of the TIIS. Given the considerable amount of uncertainty regarding inflation over long horizons, one cannot rule out that outstanding TIIS will realize a lower financing cost than nominal debt.

The amount of uncertainty regarding long-run inflation is difficult to measure, and so we consider several estimates. The first is based on long-run simulations of the Federal 
Reserve's FRB/US macroeconomic model. ${ }^{30}$ The simulations are performed by hitting the model with shocks drawn from the historical distribution of shocks from 1967:Q1 to 1999:Q4. Monetary policy is assumed to be set according to an estimated policy rule that responds to deviations of inflation from a target and of unemployment from its long-run level. The model is simulated 1500 times, each time saving the cumulative inflation over a ten-year period.

The distribution of the unexpected component of ten-year inflation (expressed at an annualized rate) that results is shown in figure $5 .{ }^{31}$ Because of the assumed policy rule, the distribution of inflation will be approximately centered around the inflation target, which in the current exercise is set to 2.5 percent. The standard deviation of the (annualized) ten-year cumulative inflation is 0.57 percentage points. Under this amount of uncertainty, we can compute the probability that ten-year inflation will fall below 1.87 percent, the level at which outstanding TIIS would break even. Under the FRB/US measure of uncertainty, the probability of inflation falling below this threshold is about 17 percent.

The FRB/US simulations might understate the amount of uncertainty about long-run inflation, though. Those simulations assume that the structure and parameters of the model are known and stable over time. The Federal Reserve's policy rule is also perfectly known and stable, and its form tends to make inflation revert back to a constant level. Structural changes to the economy and shifts in policymakers' preferences could result in more uncertainty about the long-run behavior of inflation. Moreover, the structure and parameter values from the model are determined with the benefit of hindsight, and the errors in the model are based on the in-sample fit. Predicting inflation out-of-sample would presumably be much more difficult.

\footnotetext{
${ }^{30}$ We appreciate the help of Flint Brayton, who performed the simulations with the FRB/US model. The version of the model used assumes that expectations are formed from a VAR. A description of the model can be found in Reifschneider, Tetlow, and Williams (1999).

${ }^{31}$ The standard deviation of the annualized ten-year inflation does not equal the standard deviation of inflation in any given year because the inflation rate is serially correlated.
} 
Given this consideration, it is not surprising that inflation has appeared more difficult to predict than implied in the FRB/US simulations. CBO (2000) discusses its historical performance in making five-year forecasts. From that discussion, one can construct the CBO's prediction errors for five-year average inflation (based on the GDP deflator) over the period 1976 to $1999 .^{32}$ The standard error of the CBO's prediction errors is 1.67 percentage points. Of course, a longer horizon for inflation uncertainty is relevant for assessing the relative cost of TIIS. An estimate of the amount of uncertainty over ten-year average inflation can be obtained by assuming that inflation five years ahead is completely unpredictable. In that case, the standard error of average ten-year inflation is found to be 1.49 percentage points. ${ }^{33}$ Under that level of uncertainty, the probability that TIIS will break even going forward increases to about 37 percent.

While the FRB/US estimate may understate inflation uncertainty, the estimate derived from the CBO's forecast errors estimates likely overstates it, as those errors include a period in which inflation was higher and more volatile than in more recent years. Indeed, realized (trailing) ten-year CPI inflation, shown in figure 6, has fallen in the 1980s and 1990s, following its considerable run-up in the 1970s. Judging from figure 6, one could argue that the most important factor determining long-run inflation uncertainty is not its stochastic variation around some level, but instead is the possibility of less frequent, larger shifts in the inflation process. However, it also seems that such shifts are less likely to be repeated given that policymakers have learned from the experience of the 1970s and early 1980s.

\footnotetext{
${ }^{32}$ Differences might arise from the use of the GDP deflator instead of the CPI, but forecast errors for CPI inflation were not reported.

${ }^{33}$ The standard deviation of the CBO's forecast errors for five-year average inflation over the sample is 1.67 percentage points, and that of actual five-year average inflation is 2.46 percentage points. Thus, under the assumption of independence, the standard deviation of ten-year average inflation errors is $0.5^{*}\left(1.67^{2}+2.46^{2}\right)^{0.5}$. For computing the probability of TIIS breaking even, we assume a normal distribution.
} 
Overall, a reasonable guess is that the standard deviation of annualized ten-year inflation is somewhere between $1 / 2$ and $1 \frac{1}{2}$ percentage points. As indicated above, if longrun inflation is around 2.5 percent, then this range of uncertainty suggests that the probability of breaking even on the outstanding TIIS is approximately between one-sixth and one-third. However, the probability of breaking even on the hypothetical TIIS depends importantly on the long-run level of CPI inflation, which is to a large extent determined by the policy set by the Federal Reserve. The probability can drop off sharply for slightly higher levels of long-run inflation, especially if the standard deviation is towards the lower end of the above range. On the other hand, the odds would be about even if the Federal Reserve maintained average CPI inflation near 1.80 percent.

Lastly, note that inflation uncertainty also affects the expected relative cost of the TIIS program. As discussed in section 2, inflation uncertainty increases the expected real return to the holder of a nominal bond for a given level of its yield (which, it was argued, tends to lower the yield spread between nominal securities and TIIS for a given level of inflation expectations). The flip side of that relationship is that, for a given level of interest rates, inflation uncertainty increases the expected real cost of servicing nominal debt, while the real cost of servicing TIIS is unaffected. If we assume that inflation has a long-run level of 2.5 percent and the uncertainty range discussed above, this effect pushes down the expected relative cost of a ten-year TIIS by 2 to 11 basis points (out of the 70 basis point average cost estimated above). Unfortunately, to obtain a more precise estimate of the effect on the total cost of the TIIS program, one would have to make more extensive assumptions about inflation uncertainty over different horizons up to thirty years.

\section{Conclusions}

Over the first five years of its existence, Treasury inflation-indexed debt has not been highly valued by investors and has not yet proven to be a less expensive form of 
financing for the Treasury. To some extent, the high relative cost of inflation-indexed debt to date likely reflects the difficulties associated with launching a new type of asset.

However, even over the past couple of years, when the market has had more time to adjust to TIIS, measures of ten-year inflation compensation (measured relative to off-the-run nominal Treasuries) have still fallen below comparable survey measures by more than $1 / 2$ percentage point, on average. This finding is particularly surprising if one believes that yields on nominal Treasuries contain a positive inflation risk premium, which Campbell and Shiller (1996) estimated to be between $1 / 2$ and 1 percentage points for a five-year note. Thus, the observed behavior of TIIS raises questions about whether the actual inflation risk premium is actually that large (or even positive).

The surprisingly low levels of inflation compensation may partly reflect that participation in the TIIS market to date has been fairly concentrated and that TIIS have lower liquidity than their nominal counterparts. However, these factors likely do not fully resolve the puzzle. It is doubtful that the difference in liquidity by itself can account for the low levels of inflation compensation that have been observed, especially considering that we measure inflation compensation using off-the-run nominal Treasury securities. And the lack of breadth of investor participation of course is not an exogenous factor, but simply restates the puzzle of why investors have not found TIIS more appealing.

Even though TIIS issuance to date has appeared expensive, the Treasury might find it worthwhile to sustain the program. By issuing TIIS, the Treasury has provided investors with a type of asset that was not previously available. Moreover, other debt management choices suggest that the Treasury is not concerned strictly with minimizing its current financing costs. ${ }^{34}$ For example, the Treasury currently issues securities with maturities out

\footnotetext{
${ }^{34}$ In a speech on March 14, 2002, Under Secretary of the Treasury Peter Fisher stated that the objective of debt managers is to "meet the financing needs of the federal government at the lowest cost over time." This objective could allow for issuance of securities that are currently more costly if doing so were to lower borrowing costs in the future.
} 
to ten years, even though it pays a term premium at the margin on the longer maturities compared to short-term debt. The Treasury instead likely pursues a more complicated debt management strategy that takes into consideration the relationships between its borrowing needs and the costs of issuing different types of debt over time. In this context, the optimal debt structure for the Treasury could contain some indexed debt. ${ }^{35}$

In addition, the TIIS market appears to still be evolving. Liquidity in those securities has been improving, as evidenced by the marked pick up in volume in recent years, and the investor base for those securities continues to broaden. Moreover, some investors may be more willing to enter the TIIS market after the Treasury indicated in February 2002 that it would sustain and attempt to improve the program. The behavior of the TIIS market going forward will therefore be of considerable interest.

${ }^{35}$ The academic literature on optimal debt structure focuses on the objective of smoothing tax rates, which in some cases argues for issuing debt with stable real payments. See Barro (1997) and Bohn (1990) for a discussion. 


\section{References}

Barro, Robert J. (1997), Optimal Management of Indexed and Nominal Debt, NBER Working Paper No. 6197.

Bohn, Henning (1990), Tax Smoothing with Financial Instruments, American Economic Review 80, 1217-1230.

Campbell, John Y. and Robert J. Shiller (1996), A Scorecard for Indexed Government Debt, NBER Working Paper No. 5587.

Congressional Budget Office (2002), The Budget and Economic Outlook: Fiscal Years 2003-2012, January 2002.

Congressional Budget Office (2000), The Budget and Economic Outlook: An Update, July 2000 .

Dupont, Dominique and Brian Sack (1999), "The Treasury Securities Market: Overview and Recent Developments," Federal Reserve Bulletin 85, 785-806.

Fischer, Stanley (1975), “The Demand for Index Bonds," Journal of Political Economy 83, 509-534.

Kopcke, Richard W. and Ralph C. Kimball (1999), "Inflation-Indexed Bonds: The Dog That Didn't Bark," New England Economic Review, Federal Reserve Bank of Boston, 3-24.

McCulloch , J. Huston and Levis A. Kochin (1998), "The Inflation Premium Implicit in the US Real and Nominal Term Structures of Interest Rates," Ohio State University Economics Department Working Paper \#98-12.

Reifschneider, David, Robert Tetlow, and John Williams (1999), "Aggregate Disturbances, Monetary Policy, and the Macroeconomy: The FRB/US Perspective," Federal Reserve Bulletin 85, 1-19.

Sack, Brian (2000), "Deriving Inflation Expectations from Nominal and Inflation-Indexed Treasury Yields," Journal of Fixed Income 10, 1-12.

Shen, Pu and Jonathan Corning (2002), "Can TIPS Help Identify Long-Term Inflation Expectations?" Economic Review, Federal Reserve Bank of Kansas City, 61-87.

Wilcox, David W., "The Introduction of Indexed Government Debt in the United States," Journal of Economic Perspectives 12, 219-227. 
Table 1

\section{Inflation Compensation and Survey Measure of Inflation Expectations}

\begin{tabular}{rccc}
\hline & $\begin{array}{c}\text { Inflation } \\
\text { Compensation } \\
\text { Measure } \\
(1)\end{array}$ & $\begin{array}{c}\text { Survey Measure of } \\
\text { Inflation } \\
\text { Expectations }\end{array}$ & Difference \\
\hline 1997 Q1 & 3.29 & $(2)$ & $(1)-(2)$ \\
Q2 & 3.18 & 2.85 & 0.29 \\
Q3 & 2.74 & 3.00 & 0.33 \\
Q4 & 2.43 & 2.65 & -0.26 \\
1998 Q1 & 2.04 & 2.60 & -0.22 \\
Q2 & 1.99 & 2.50 & -0.56 \\
Q3 & 1.58 & 2.50 & -0.51 \\
Q4 & 1.10 & 2.50 & -0.92 \\
1999 Q1 & 1.45 & 2.30 & -1.40 \\
Q2 & 1.90 & 2.50 & -0.85 \\
Q3 & 2.15 & 2.50 & -0.60 \\
Q4 & 2.24 & 2.50 & -0.35 \\
2000 Q1 & 2.37 & 2.50 & -0.26 \\
Q2 & 2.28 & 2.50 & -0.13 \\
Q3 & 2.05 & 2.50 & -0.22 \\
Q4 & 1.83 & 2.50 & -0.45 \\
& & & -0.67 \\
2001 Q1 & 1.78 & 2.50 & -0.72 \\
Q2 & 2.13 & 2.50 & -0.37 \\
Q3 & 1.83 & 2.50 & -0.67 \\
Q4 & 1.64 & 2.55 & -0.53 \\
\hline 2002 Q1 & 1.97 & 2.50 & \\
& & & \\
\hline
\end{tabular}

Inflation compensation is the quarterly average of the measure described in the text, which is based on the difference between the yields on TIIS and off-the-run nominal securities. The survey measure is the median response for ten-year expected inflation from a survey by the Federal Reserve Bank of Philadelphia. 
Table 2

Typical Bid/Ask Spreads for Treasury Securities

$1 / 32$ nds of price

\begin{tabular}{ccc}
\hline & $\begin{array}{c}\text { Maturities of } \\
5 \text { years or less }\end{array}$ & $\begin{array}{c}\text { Maturities greater } \\
\text { than 5 years }\end{array}$ \\
\hline On-the-run Nominal & $1 / 4$ & $1 / 4$ to $1 / 2$ \\
Off-the-run Nominal & $1 / 4$ to $1 / 2$ & $1 / 4$ to 1 \\
Inflation-indexed & 1 to 2 & 2 to 6
\end{tabular}

These spreads are for moderate-sized trades. Data are based on an informal survey of dealers by the Federal Reserve Bank of New York taken in early 2002. 
Table 3

Estimated Costs of TIIS: Static Nominal Issuance

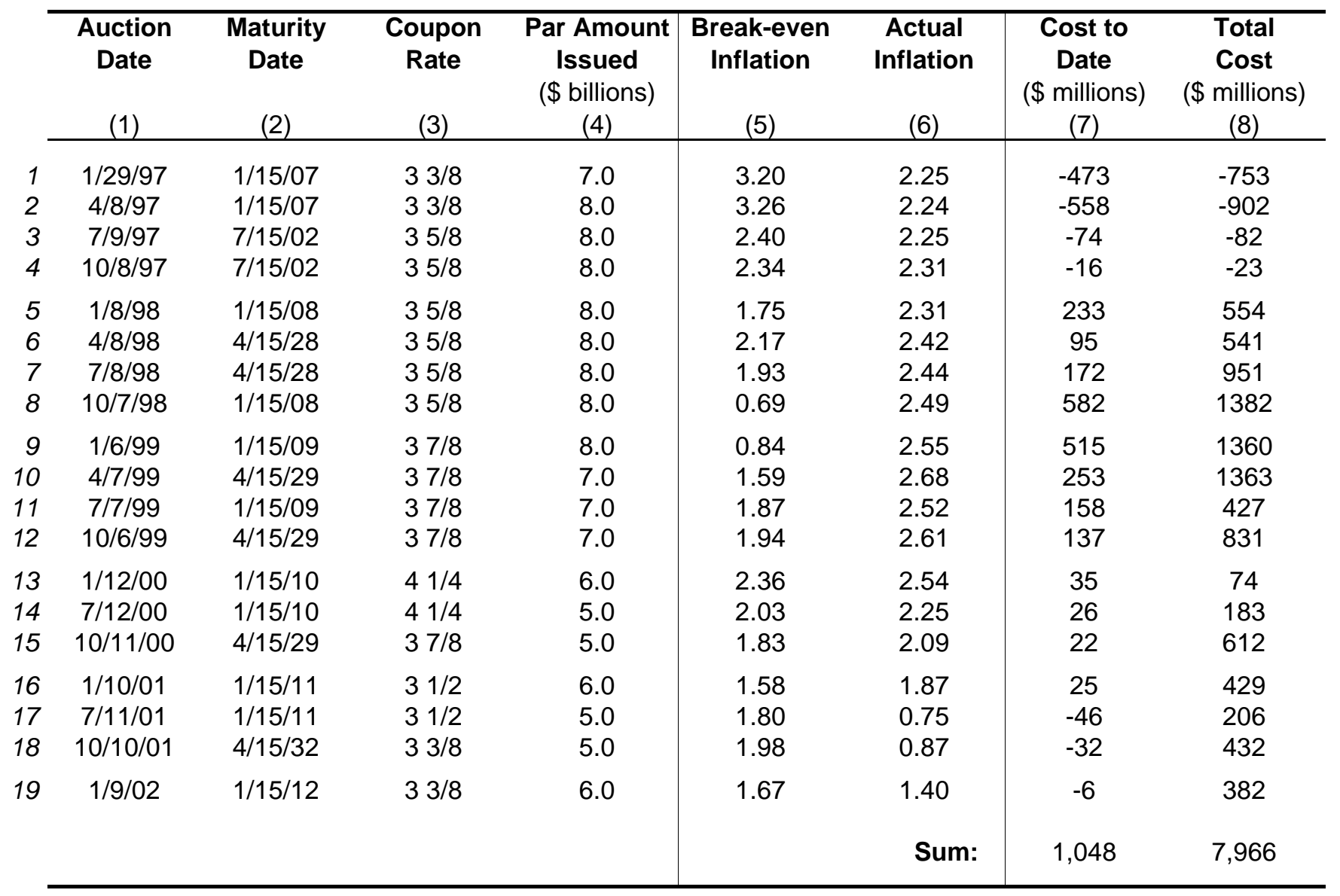

Cost figures are measured as the present value of the differences in the payments on the TIIS and the nominal securities. All cost figures are measured as of May 20, 2002. Column (7) shows the cost based on inflation through that date (accounting for the indexation lag). Column (8) shows the total cost if future inflation follows the path assumed by the CBO. 
Table 4

Estimated Costs of TIIS: Dynamic Nominal Issuance

\begin{tabular}{|c|c|c|c|c|}
\hline $\begin{array}{c}\text { Auction } \\
\text { Date } \\
(1) \\
\end{array}$ & $\begin{array}{c}\text { Maturity } \\
\text { Date } \\
(2) \\
\end{array}$ & $\begin{array}{c}\text { Coupon } \\
\text { Rate } \\
(3) \\
\end{array}$ & $\begin{array}{c}\text { Par Amount } \\
\text { Issued } \\
\text { (\$ billions }) \\
(4) \\
\end{array}$ & $\begin{array}{c}\text { Total } \\
\text { Cost } \\
(\$ \text { millions }) \\
(5) \\
\end{array}$ \\
\hline $\begin{array}{c}1 / 29 / 97 \\
4 / 8 / 97 \\
7 / 9 / 97 \\
10 / 8 / 97\end{array}$ & $\begin{array}{l}1 / 15 / 07 \\
1 / 15 / 07 \\
7 / 15 / 02 \\
7 / 15 / 02\end{array}$ & $\begin{array}{l}33 / 8 \\
35 / 8 \\
35 / 8 \\
35 / 8\end{array}$ & $\begin{array}{l}7.0 \\
8.0 \\
8.0 \\
8.0\end{array}$ & $\begin{array}{l}-640 \\
-942 \\
-97 \\
-35\end{array}$ \\
\hline $\begin{array}{c}1 / 8 / 98 \\
4 / 8 / 98 \\
7 / 8 / 98 \\
10 / 7 / 98\end{array}$ & $\begin{array}{l}1 / 15 / 08 \\
4 / 15 / 28 \\
4 / 15 / 28 \\
1 / 15 / 08\end{array}$ & $\begin{array}{l}35 / 8 \\
35 / 8 \\
35 / 8 \\
35 / 8\end{array}$ & $\begin{array}{l}8.0 \\
8.0 \\
8.0 \\
8.0\end{array}$ & $\begin{array}{c}506 \\
511 \\
732 \\
1432\end{array}$ \\
\hline $\begin{array}{c}1 / 6 / 99 \\
4 / 7 / 99 \\
7 / 7 / 99 \\
10 / 6 / 99\end{array}$ & $\begin{array}{l}1 / 15 / 09 \\
4 / 15 / 29 \\
1 / 15 / 09 \\
4 / 15 / 29\end{array}$ & $\begin{array}{l}37 / 8 \\
37 / 8 \\
37 / 8 \\
37 / 8\end{array}$ & $\begin{array}{l}8.0 \\
7.0 \\
7.0 \\
7.0\end{array}$ & $\begin{array}{c}1336 \\
1240 \\
471 \\
706\end{array}$ \\
\hline $\begin{array}{c}1 / 12 / 00 \\
7 / 12 / 00 \\
10 / 11 / 00\end{array}$ & $\begin{array}{l}1 / 15 / 10 \\
1 / 15 / 10 \\
4 / 15 / 29\end{array}$ & $\begin{array}{l}41 / 4 \\
41 / 4 \\
37 / 8\end{array}$ & $\begin{array}{l}6.0 \\
5.0 \\
5.0\end{array}$ & $\begin{array}{l}117 \\
357 \\
646\end{array}$ \\
\hline $\begin{array}{c}1 / 10 / 01 \\
7 / 11 / 01 \\
10 / 10 / 01\end{array}$ & $\begin{array}{l}1 / 15 / 11 \\
1 / 15 / 11 \\
4 / 15 / 32\end{array}$ & $\begin{array}{l}31 / 2 \\
31 / 2 \\
33 / 8\end{array}$ & $\begin{array}{l}6.0 \\
5.0 \\
5.0\end{array}$ & $\begin{array}{l}414 \\
299 \\
371\end{array}$ \\
\hline $1 / 9 / 02$ & $1 / 15 / 12$ & 3 3/8 & $\begin{array}{l}6.0 \\
\text { Sum: }\end{array}$ & $\begin{array}{c}351 \\
7,773\end{array}$ \\
\hline
\end{tabular}

Cost figures are measured as the present value of the differences in the payments on TIIS and nominal securities as of May 20, 2002. The calculation assumes that the yield curve reverts to its average shape over the next two years and that future inflation follows the path assumed by the CBO. 
Figure 1

Ten-year Treasury Yields and Inflation Compensation

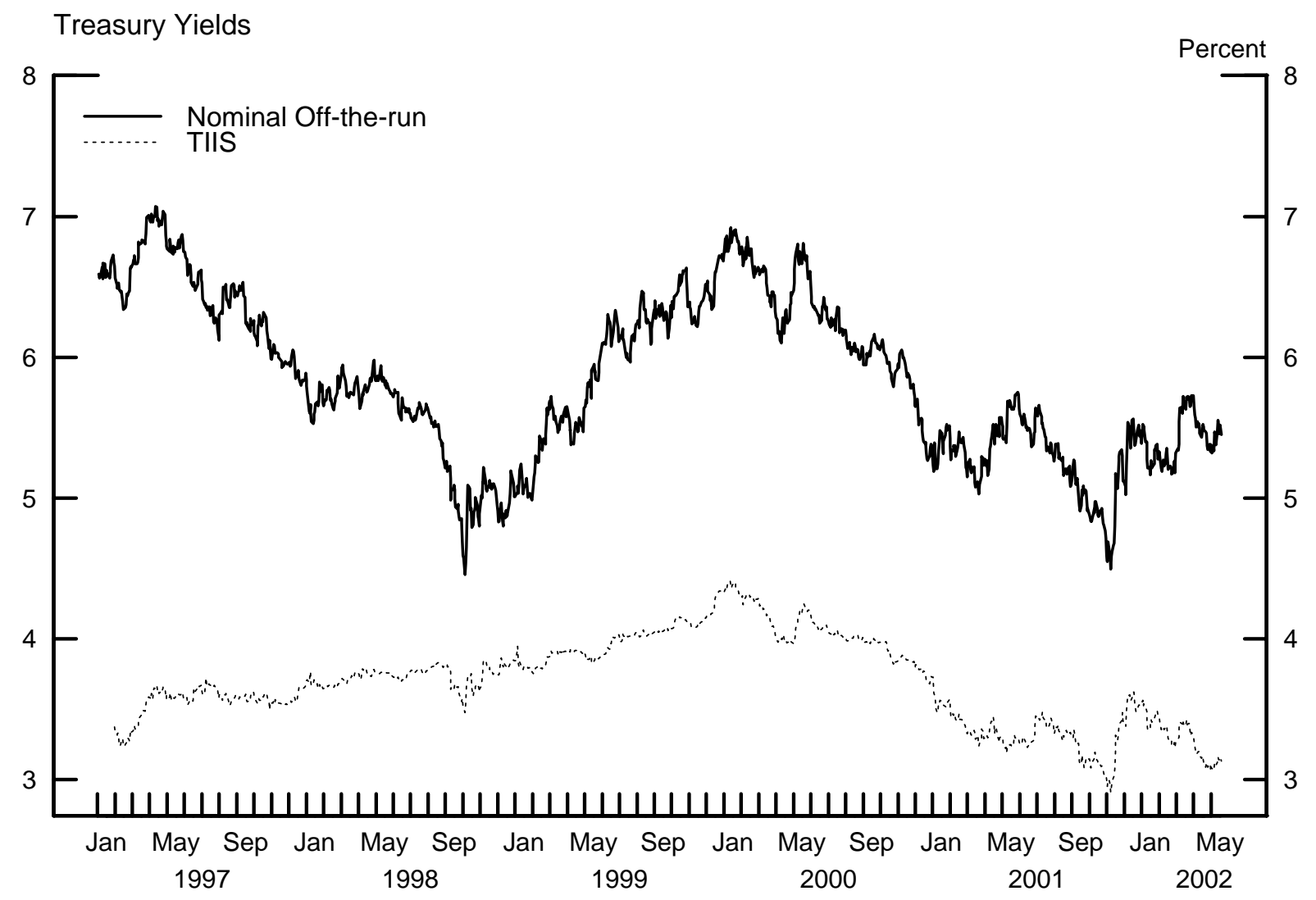

Inflation Compensation

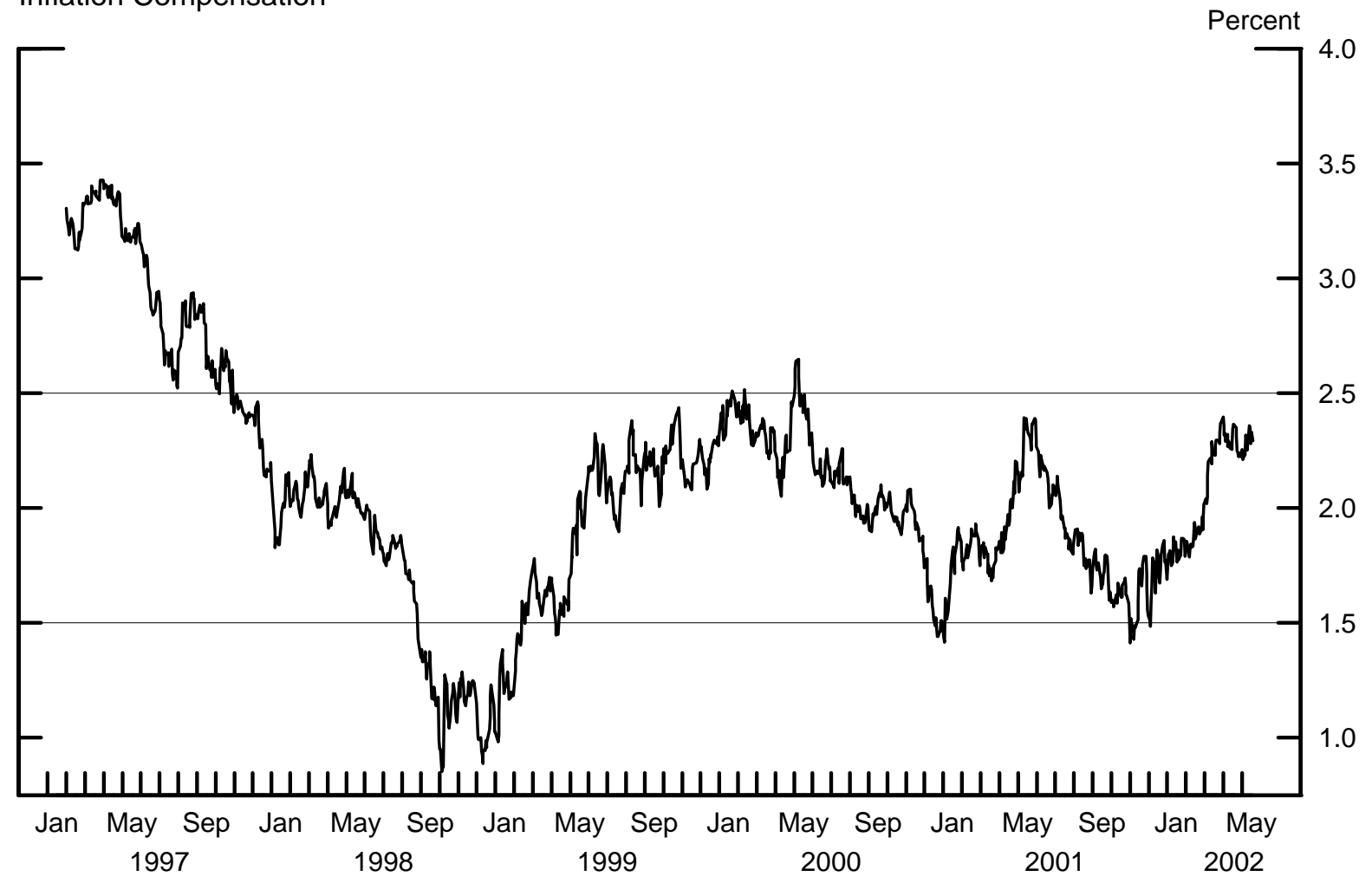

Data are through May 20, 2002. 
Figure 2

\section{CPI Inflation and Expectation Error}

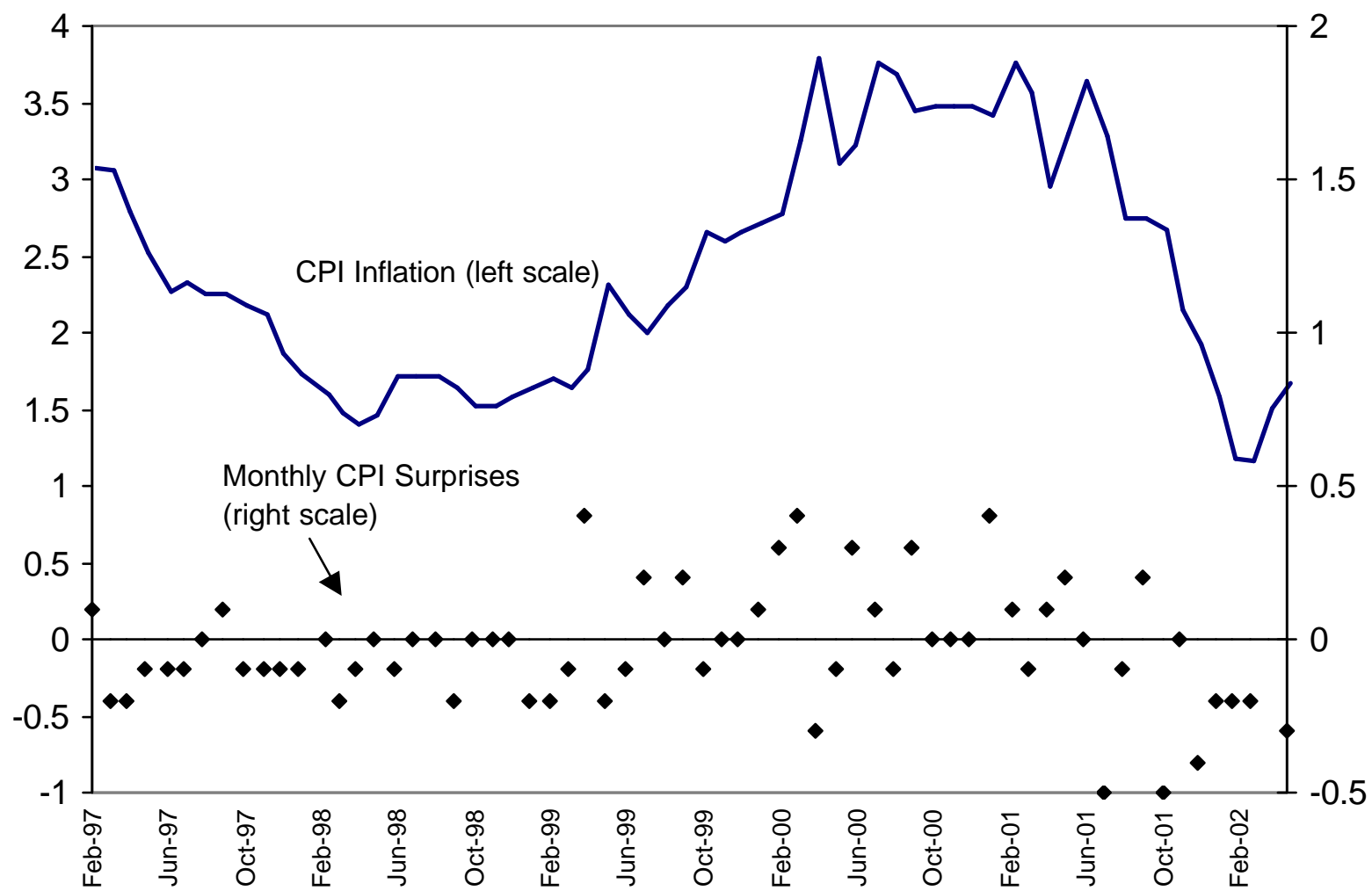

$\mathrm{CPI}$ series is the twelve-month change in the non-seasonally adjusted overall CPI index.

Data are through April 2002. 
Figure 3

\section{TIIS Yield Curves}

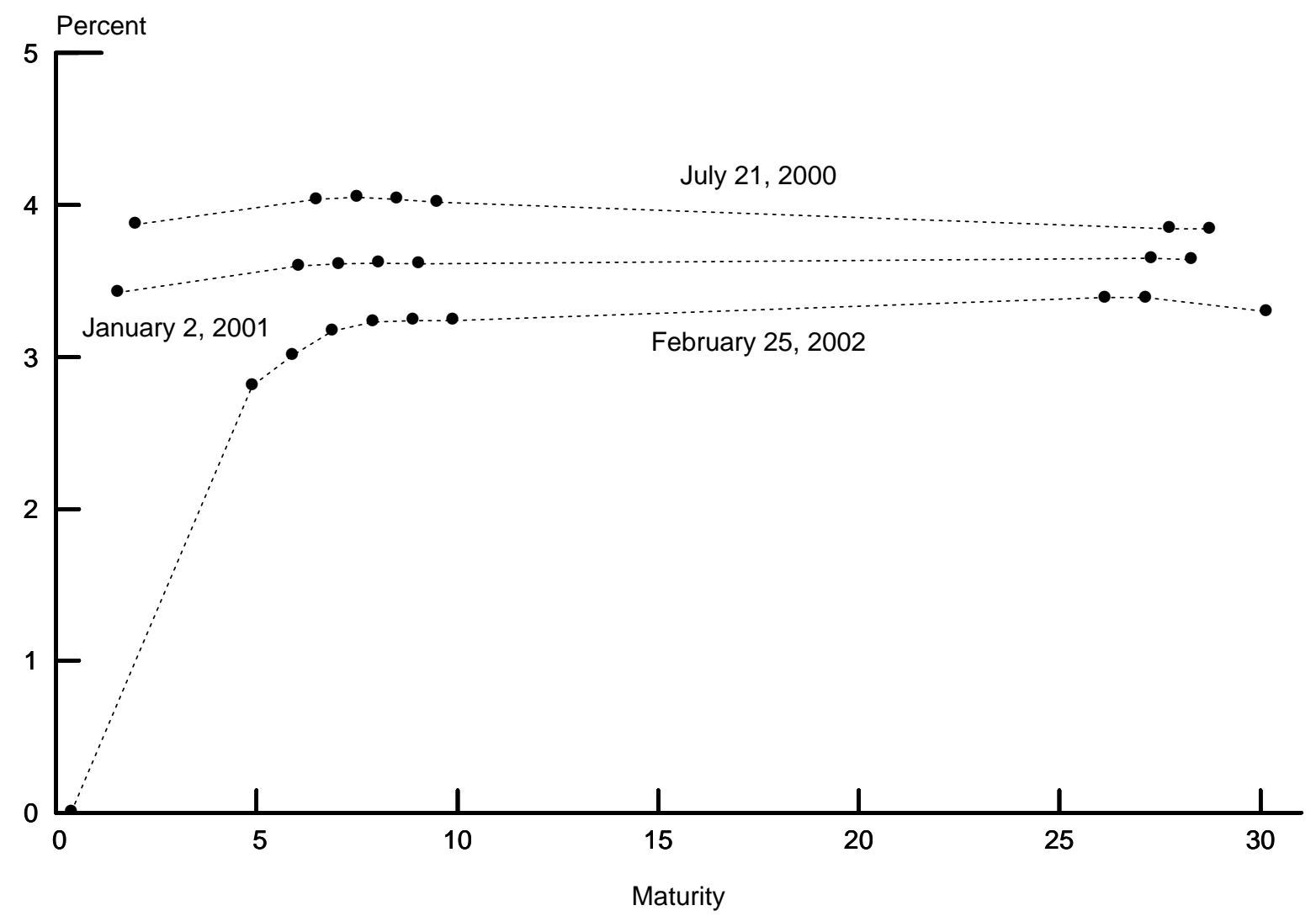


Figure 4

TIIS Trading Turnover

(13-week Moving Average of Trading Volume Relative to Outstanding Debt)

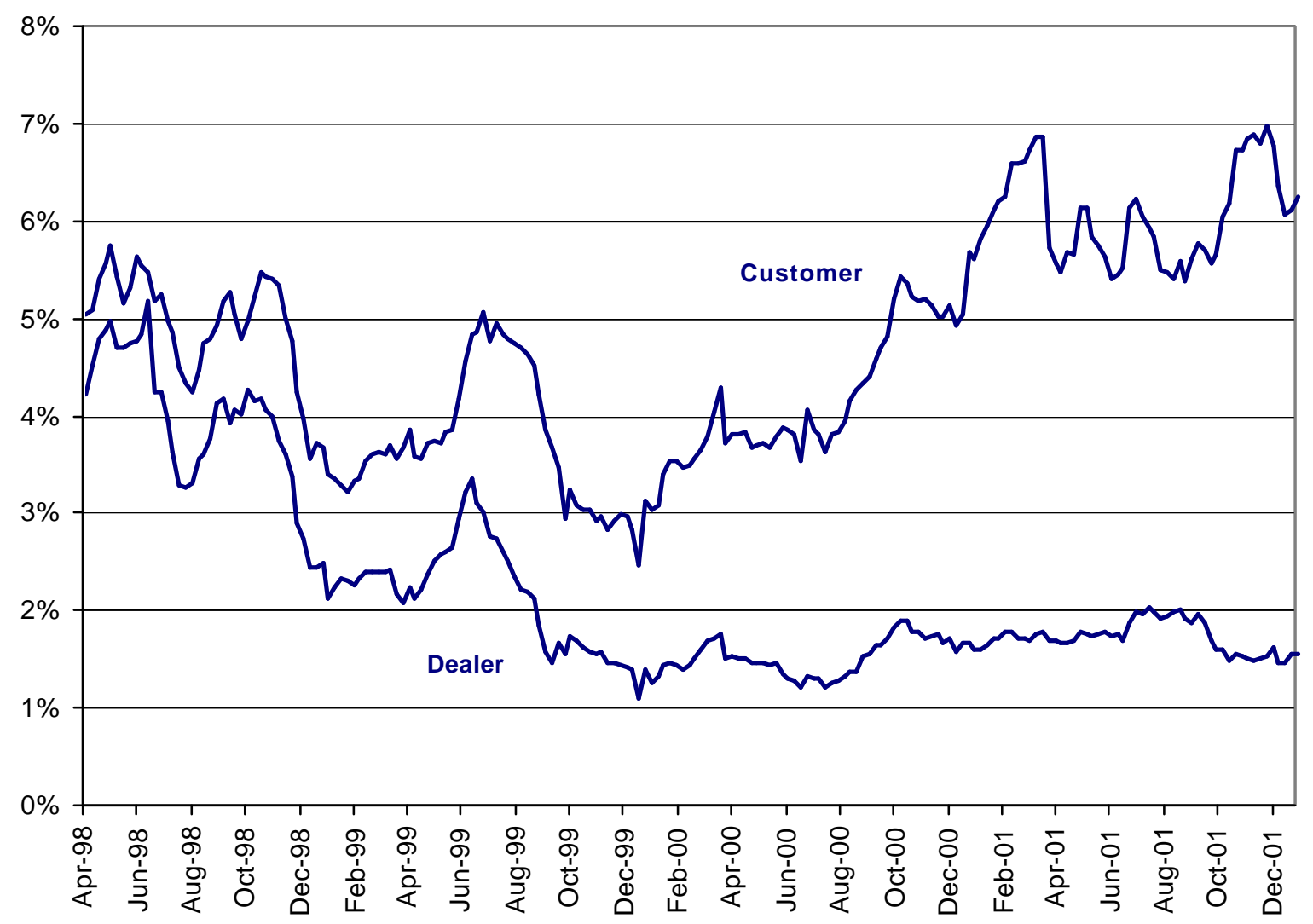

Data are through January 2002. 
Figure 5

Probability Distribution of Inflation over Ten Years

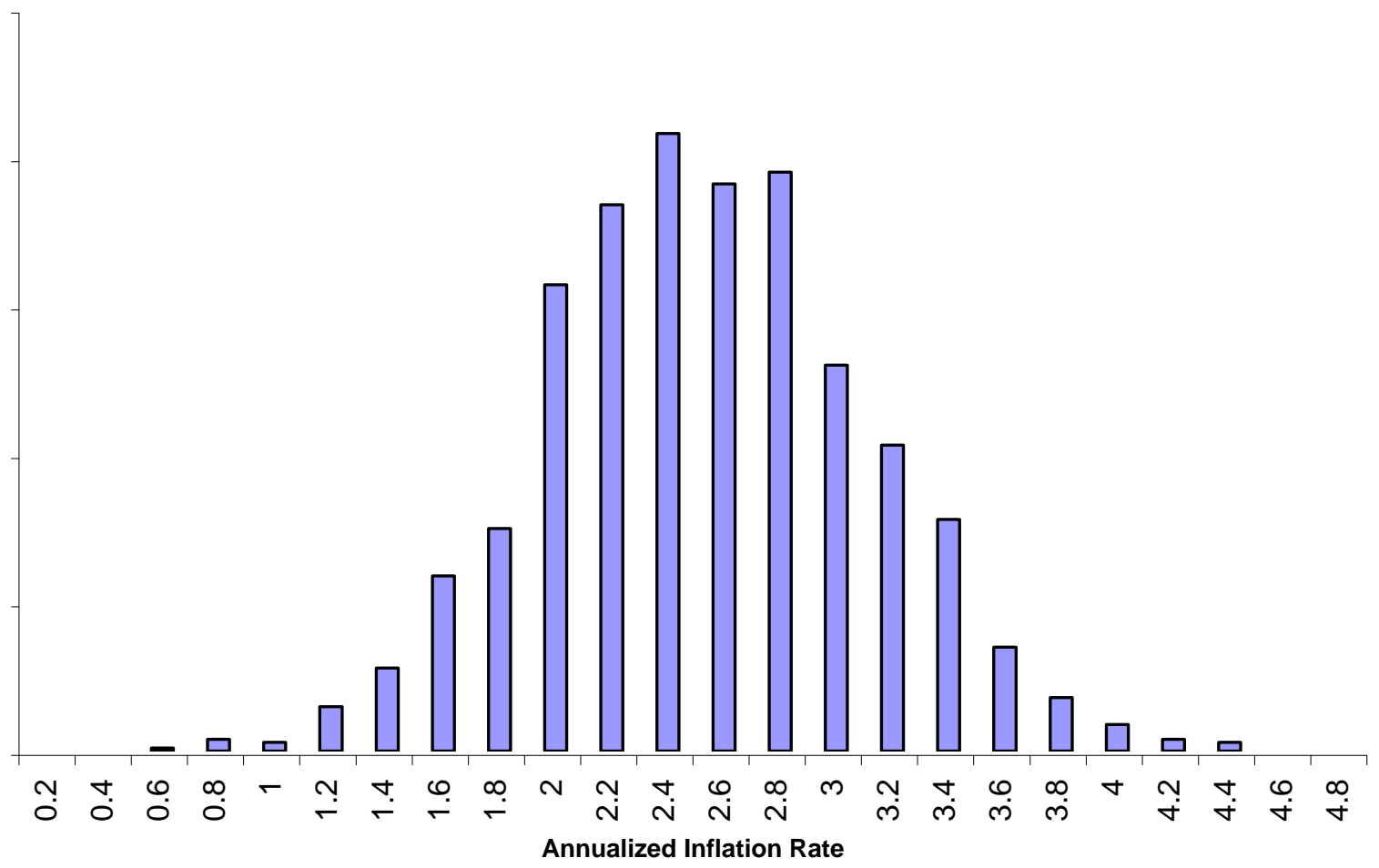

Based on FRB/US Simulations with an inflation target of 2.5 percent. 
Figure 6

Ten-year CPI Inflation

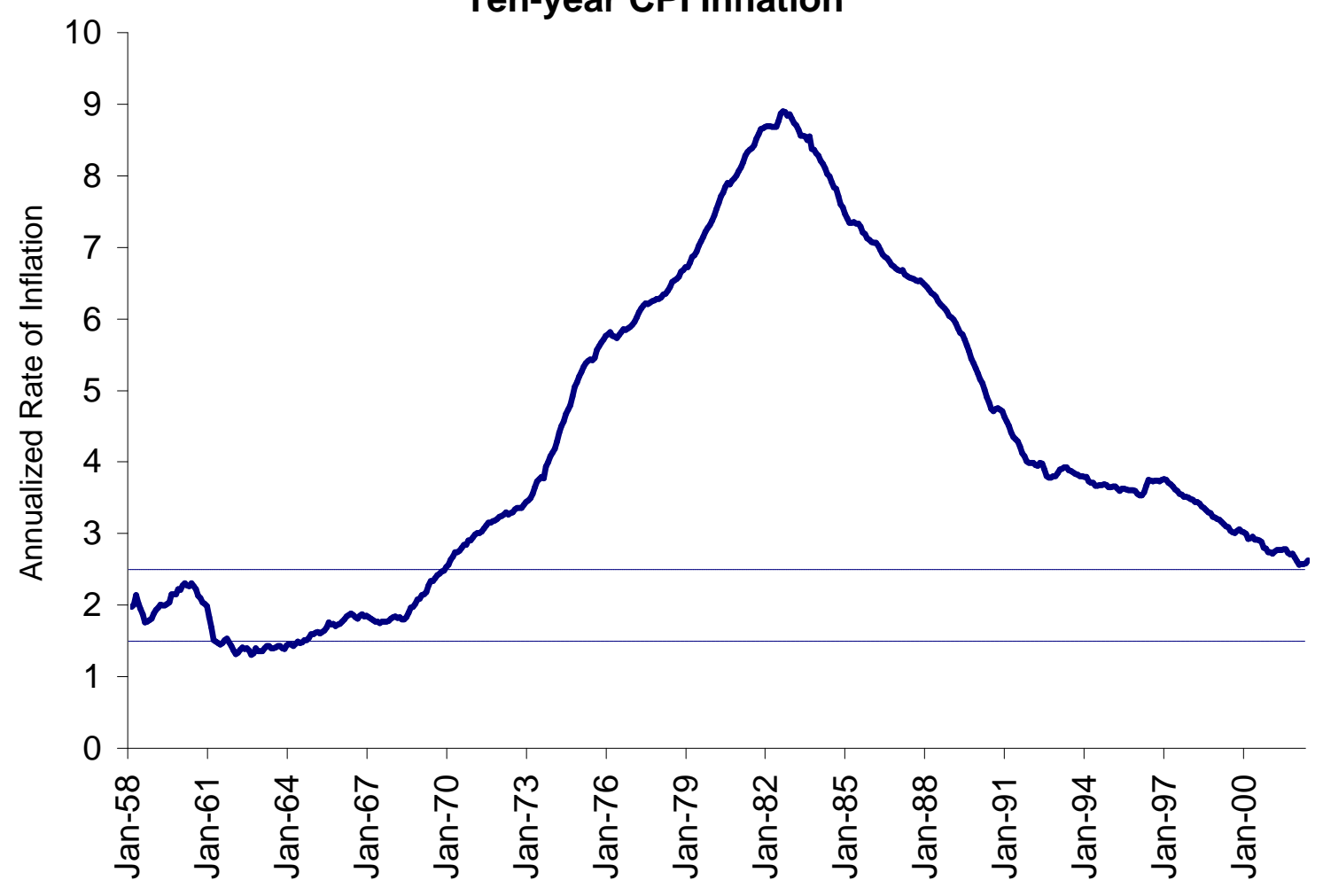

Data are through April 2002. 